\title{
Circumspective
}

\section{The Therapeutic Potential of Psychedelic Drugs: Past, Present, and Future}

\author{
Robin L Carhart-Harris*,I and Guy M Goodwin ${ }^{2}$ \\ 'Psychedelic Research Group, Centre for Psychiatry, Division of Brain Sciences, Faculty of Medicine, Imperial College London, London, UK; \\ ${ }^{2}$ University of Oxford Department of Psychiatry and Oxford Health NHS Foundation Trust, Warneford Hospital, Oxford, UK
}

Plant-based psychedelics, such as psilocybin, have an ancient history of medicinal use. After the first English language report on LSD in 1950, psychedelics enjoyed a short-lived relationship with psychology and psychiatry. Used most notably as aids to psychotherapy for the treatment of mood disorders and alcohol dependence, drugs such as LSD showed initial therapeutic promise before prohibitive legislature in the mid-1960s effectively ended all major psychedelic research programs. Since the early 1990s, there has been a steady revival of human psychedelic research: last year saw reports on the first modern brain imaging study with LSD and three separate clinical trials of psilocybin for depressive symptoms. In this circumspective piece, RLC-H and GMG share their opinions on the promises and pitfalls of renewed psychedelic research, with a focus on the development of psilocybin as a treatment for depression.

Neuropsychopharmacology (2017) 42, 2105-2113; doi:10.1038/npp.2017.84; published online 17 May 2017

\section{THE THERAPEUTIC POTENTIAL OF PSYCHEDELIC DRUGS: TEMPERED OPTIMISM (RLC-H)}

\begin{abstract}
"Your assumptions are your windows on the world. Scrub them off every once in a while, or the light won't come in." (Isaac Asimov, 1919-1992)
\end{abstract}

\section{A BRIEF HISTORY OF PSYCHEDELIC RESEARCH}

Psychedelic drugs (Psychedelic is a neologism that combines the words psychē ( $\psi \cup \chi \dot{\eta}$, 'soul') and dēloun $(\delta \eta \lambda$ o v $\nu$, 'to make visible, to reveal'), to denote 'mind-revealing' in reference to the category of drugs in question. I use the term in preference to 'hallucinogens' due to the latter's arguably misleading emphasis on these compounds' hallucinogenic properties. When using the term 'psychedelics' I refer to those compounds with appreciable serotonin $2 \mathrm{~A}$ receptor agonist properties that can alter consciousness in a marked and novel way. LSD can be considered the prototypical or 'referencestandard' psychedelic.) awakened a significant cultural zeitgeist in mid-twentieth century (Stevens, 1987, see Table 1). Catalyzed by early reports on the unique potency and remarkable subjective effects of lysergic acid diethylamide (LSD) in the early 1950s, psychedelics, and particularly LSD, became widely used by psychologists and psychiatrists in

\footnotetext{
*Correspondence: Dr RL Carhart-Harris, Psychedelic Research Group, Centre for Psychiatry, Division of Brain Sciences, Faculty of Medicine, Imperial College London, London WI2 ONN, UK, Tel: +44 0207594 7992, Fax: +440 207594 8921, E-mail: r.carhart-harris@imperial.ac.uk Received 21 March 2017; revised 10 April 2017; accepted 20 April 2017; accepted article preview online 26 April 2017
}

research and clinical practice, with tens of thousands of patients estimated to have been treated with 'psychedelic psychotherapy' over a period of about 15 years (Grinspoon and Bakalar, 1979). From the mid-60s, psychedelic research was increasingly prevented from having the capacity to inform and potentially advance thinking and practice in psychology and psychiatry, but as popular and countercultural movements increasingly embraced the drugs, their societal impact skyrocketed (Grinspoon and Bakalar, 1979; Lee and Shlain, 1992; Stevens, 1987).

\section{THE PRESENT REVIVAL}

Human psychedelic research fell into a 25-year hiatus before scientists in Germany (Hermle et al, 1992), the United States (Strassman and Qualls, 1994), and Switzerland (Vollenweider et al, 1997) began its revival. There now exists a foundation of human neuroimaging (Carhart-Harris et al, 2012a, 2016d; Daumann et al, 2010; Muthukumaraswamy et al, 2013; Palhano-Fontes et al, 2015; Preller et al, 2017; Riba et al, 2004, 2006; Vollenweider et al, 1997), psychology (Carhart-Harris et al, 2015, 2016c; Carter et al, 2007; Gouzoulis-Mayfrank et al, 2005; Griffiths et al, 2006; MacLean et al, 2011; Schmid et al, 2015), and psychopharmacology studies with psychedelics (Kometer et al, 2012; Preller et al, 2017; Valle et al, 2016; Vollenweider et al, 1998).

These foundational studies complement a small number of early phase clinical trials (Table 2). There are now positive preliminary reports on the safety and tolerability of psilocybin for obsessive compulsive disorder (Moreno et al, 2006), psilocybin, and LSD for end-of-life psychological distress (Gasser et al, 2014; Griffiths et al, 2016; Grob et al, 2011; 
Table I Notable Landmarks of Mid-Twentieth Century Psychedelic Research Plus Events of Cultural Significance

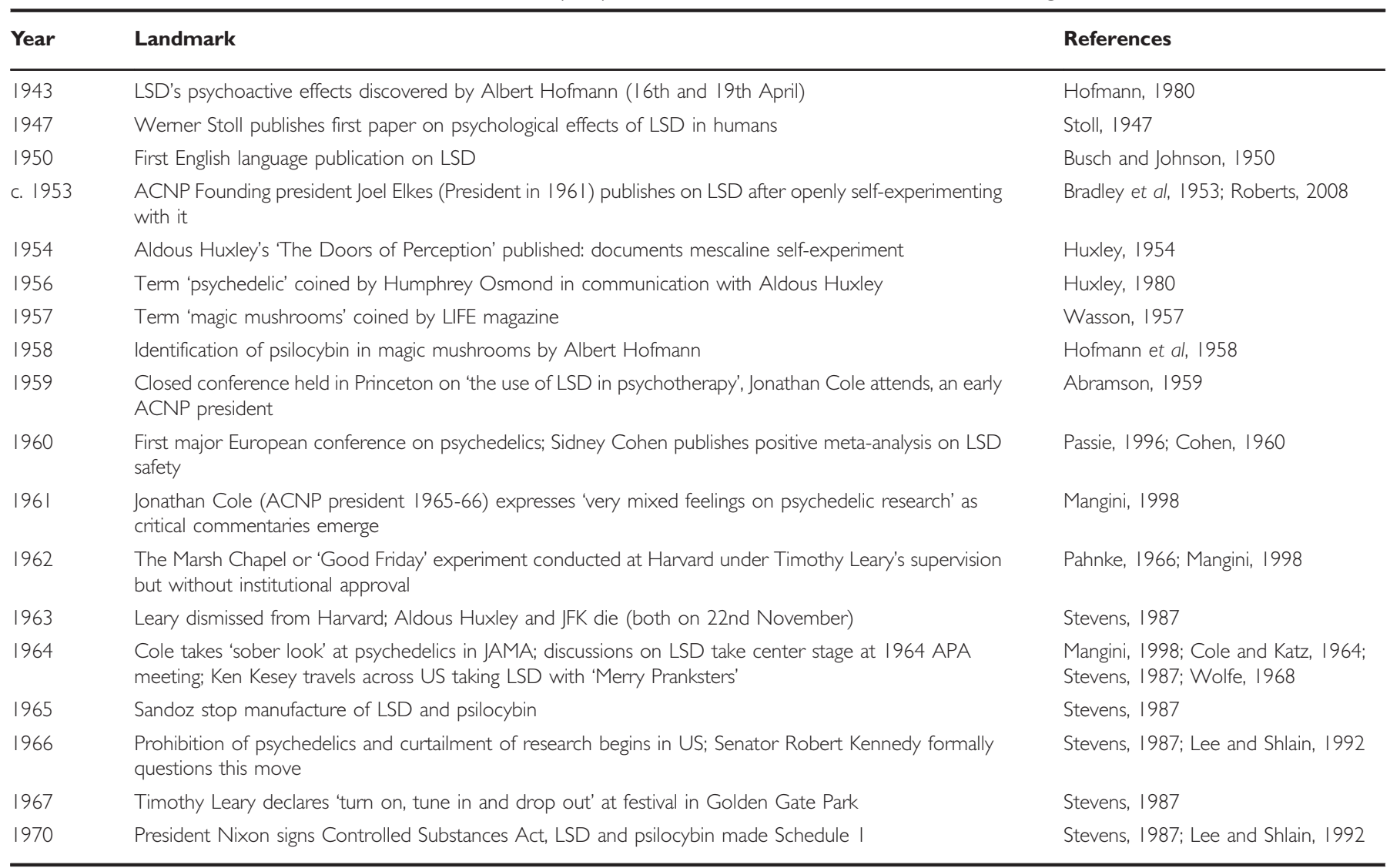

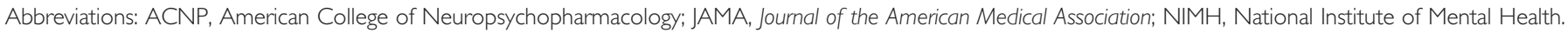

Ross et al, 2016), psilocybin for alcohol (Bogenschutz et al, 2015), and tobacco addiction (Johnson et al, 2014) and ayahuasca (Osorio Fde et al, 2015) and psilocybin for major depressive disorder (Carhart-Harris et al, 2016a,b). An important caveat here, is that many of these trials report on small sample sizes and would best be described as 'safety and tolerability' studies by conventional standards (Schunemann et al, 2006), and while all of them do report outcomes consistent with potential efficacy, most have not been appropriately designed to demonstrate it conclusively. GMG critically discusses two of the largest and better designed trials in the next section (Griffiths et al, 2016; Ross et al, 2016).

\section{PSYCHEDELICS FOR MENTAL ILLNESS}

Plant-based psychedelics have been used for hundreds if not thousands of years for holistic healing (Hofmann, 1980) and there remains an active culture of self-medication with psychedelics for mental health (Carhart-Harris and Nutt, 2010; Waldman, 2017). Contrary to the alarmist campaigning that so negatively affected perceptions of psychedelics after the 1960s, subjective (Carhart-Harris and Nutt, 2010, 2013; van Amsterdam et al, 2015), naturalistic/ observational (Bouso et al, 2012), and population-based data (Hendricks et al, 2015) indicate a positive association between psychedelic drug use and mental health, albeit with some important caveats, which will be discussed below.
Progressing to more controlled medical use, psychedelics piqued the interest of psychologists and psychiatrists in the 1950s, who noted early on that they may 'serve as new tools for shortening psychotherapy' (Busch and Johnson, 1950). A recent meta-analysis of 19 studies of psychedelics for mood disorders published between 1949 and 1973 found that 79\% of patients showed 'clinically judged improvement' post treatment (Rucker et al, 2016). Moreover, a meta-analysis of studies of LSD for alcoholism performed in the 50-60s was similarly supportive of its potential (Krebs and Johansen, 2012). The absence of standardized diagnostic techniques, measures of symptom severity, and lack of randomization and control conditions in these studies needs to be properly heeded, but equally, it would be self-defeating to dismiss their findings outright.

The modern era of controlled research with psychedelics has seen the adoption of more careful experimental designs, together with a more critical approach to outcomes. In 2006, a double-blind randomized controlled (DB-RC) study compared the acute and longer-term psychological effects of single high doses of psilocybin (30 mg) and methylphenidate $(40 \mathrm{mg})$ in healthy volunteers. Significantly, greater improvements in psychological well-being were observed after psilocybin than methylphenidate at the 2-month end point and more than half considered their psilocybin experience to be among the most personally meaningful experiences of their lives (Griffiths et al, 2006). Since then, the focus has shifted to include patients with symptoms of 


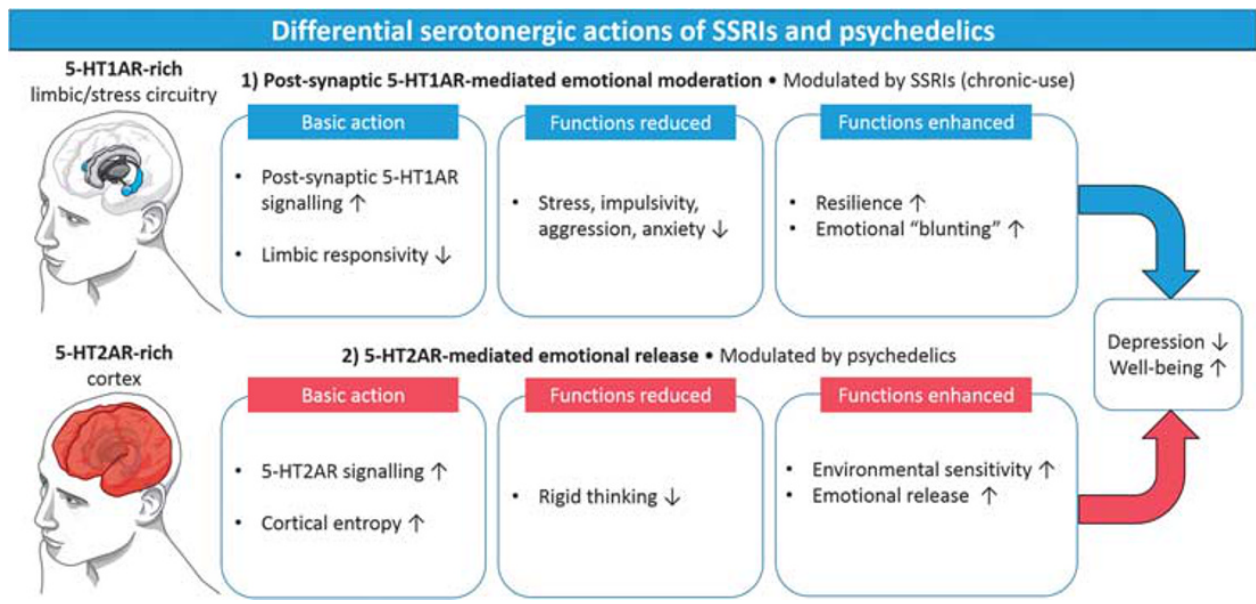

Figure I A bipartite model of serotonergic functioning focused on the effects of post-synaptic 5-HTIAR and 5-HT2AR signaling. The more pronounced effects of chronically used SSRIs on post-synaptic 5-HTIAR signaling is hypothesized to relate to their anti-stress, pro-coping properties but also their tendency to moderate or 'blunt' emotional responsiveness. The direct 5-HT2AR agonist properties of psychedelics are hypothesized to relate to their proclivity to enhance sensitivity to the environment as well as facilitate emotional release, which, when combined with psychological support, is hypothesized to be therapeutically potent.

depression and anxiety. Three DB-RC trials have assessed the impact of a single dose of psilocybin on depressive symptoms in patients with life-threatening cancer (Griffiths et al, 2016; Grob et al, 2011; Ross et al, 2016) and an open-label trial of psilocybin for treatment-resistant depression (TRD) has been completed (Carhart-Harris et al, 2016a,b). All four studies, and particularly the three most recent, found rapid, marked, and enduring anti-anxiety and depression effects post psilocybin. Significant improvements in obsessive compulsive disorder symptoms (Moreno et al, 2006) and alcohol dependence with psilocybin (Bogenschutz et al, 2015), anxiety with LSD (Gasser et al, 2014), and depression with ayahuasca (Osorio Fde et al, 2015; Sanches et al, 2016) help supplement the case for psilocybin and inspire questions regarding the potential generalized therapeutic action of psychedelics.

Focusing on antidepressant action, psilocybin, and psychedelics more generally, share some similarities with conventional antidepressants (ie, serotonergic modulation); however, they also possess some important differences. Regarding similarities, an altered relationship with the environment may be critical to recovery with selective serotonin reuptake inhibitors (Belsky, 2016; Harmer and Cowen, 2013) and heightened sensitivity to the environment is a cardinal feature of the psychedelic state (Carhart-Harris et al, 2015; Hartogsohn, 2016; Kaelen et al, 2015), perhaps due to psychedelics' direct agonist action at the 5-HT2AR (Dressler et al, 2016; Fiocco et al, 2007; Jokela et al, 2007). Regarding differences, the chronic antidepressant action of SSRIs includes reduced limbic responsiveness and emotional moderation or blunting, likely via post-synaptic 5-HT1A receptor signaling (Cowen and Browning, 2015; Deakin and Graeff, 1991; McCabe et al, 2010); this contrasts with the greater role for 5-HT2AR signaling with psychedelics, and emphasis on emotional release (Carhart-Harris et al, 2012b; Roseman et al, 2016; Watts et al, 2017). Contrasting approaches to emotion may be a fundamental difference between the SSRI and psychedelic treatment models (Figure 1).
In my opinion, if the science is allowed to progress without the kind of political interference that has hindered it in the past, psilocybin with psychological support (PwPS) will become an early option in the treatment of depression. I predict that PwPS will be found to have important areas of superiority over current early interventions such as SSRIs and CBT. Specifically, PwPS's rapid and enduring action with minimal exposure, positive side-effect profile, and specific therapeutic action-working to address rather than suppress or side-step aversive memories and emotions, may set it apart from the alternative, largely 'palliative' treatment options for major depression.

"That is the essence of science: ask an impertinent question, and you are on the way to a pertinent answer." (Jacob Bronowski, 1908-1974)

Another consideration is that chronic antidepressant medication strategies appear to have a muting effect on psilocybin's acute and putative antidepressant effects (Bonson et al, 1996; Bonson and Murphy, 1996), implying that treating medication-heavy, treatment-resistant depressed patients with psilocybin will be especially challenging (Carhart-Harris et al, 2016a,b). Medication discontinuation would likely be required prior to receipt of the psychedelic and this often requires careful management (Baldwin et al, 2007).

\section{THE THERAPEUTIC POTENTIAL OF PSYCHEDELIC DRUGS: UPBEAT PESSIMISM (GMG)}

"What Leary took down with him was the central illusion of a whole life-style that he helped to create... a generation of permanent cripples, failed seekers, who never understood the essential old mystic fallacy of the Acid Culture: the desperate assumption that somebody, or at least some force, is tending the Light at the end of the tunnel." (Hunter S Thompson. Fear and Loathing in Las Vegas, 1971) 
Table 2 Clinical Trials Involving Psychedelics Published During the Present 'Second Wave' of Psychedelic Research

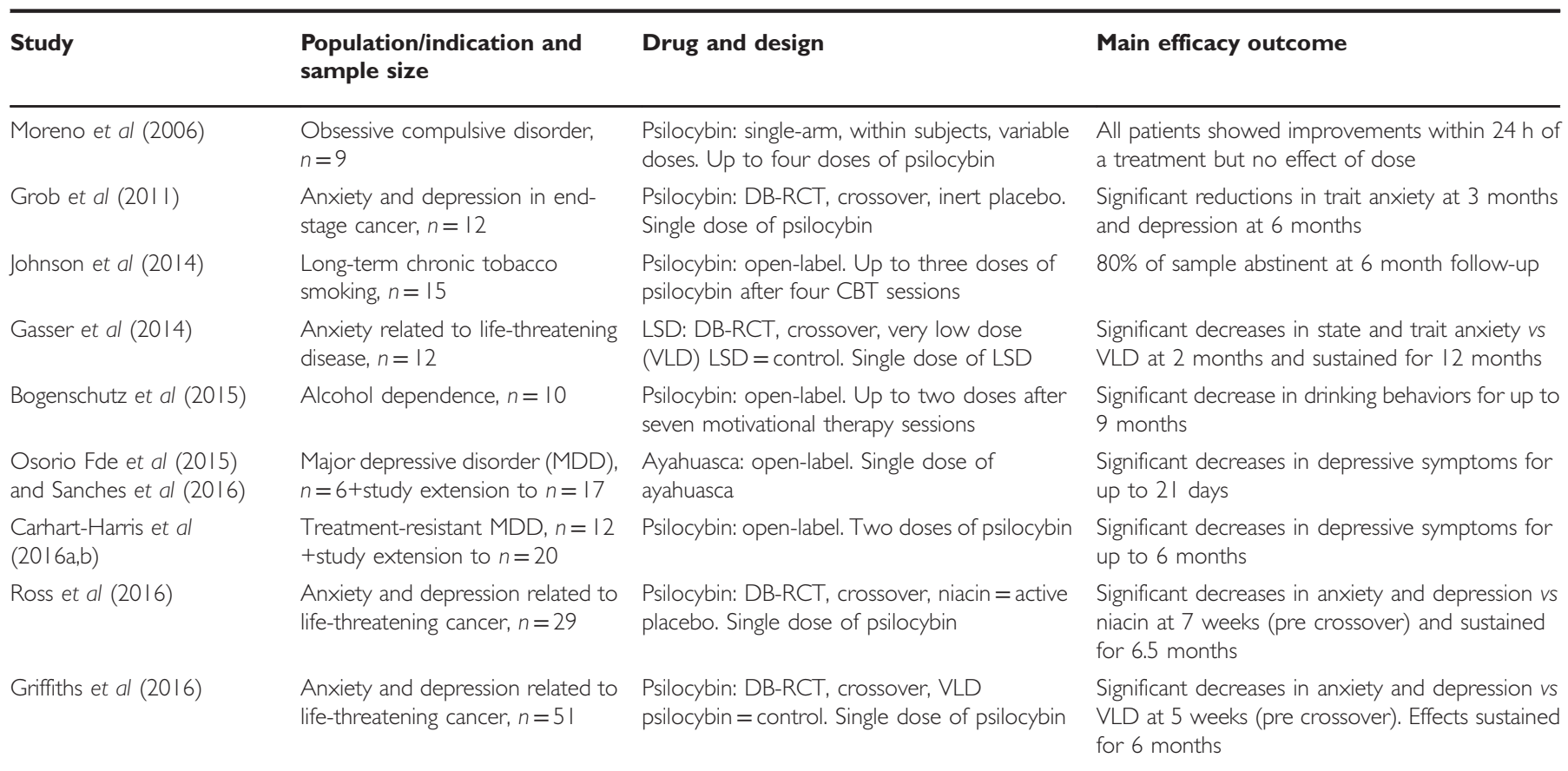

Abbreviations: DB-RCT, double-blind randomised controlled trial; VLD, very low dose; MDD, major depressive disorder; TRD, treatment-resistant depression.

\section{FINDING SIGNAL AMIDST THE PSYCHEDELIC NOISE}

As a clinician long committed to the view that neuroscience should inform psychiatry, psychedelics have always looked like a serious opportunity. Their structure and pharmacology inspired a generation of neurochemists to understand neurotransmitters and their receptors. And, the very idea that drugs could usefully change the experience of distressed patients with psychiatric disorders underpinned the revolution in psychopharmacology in the three decades from 1950. However, the 'illegal' status of psychedelics stopped serious research in humans until quite recently, as RLC-H has explained.

So, can psychedelics take us back to the future? I understand the appeal that RLC-H feels for their potential. However, the difficulty in finding a medical role for psilocybin must not be underestimated. It is worth reflecting on what we have learned from the very recently published clinical trials. Their strengths and their weaknesses define the challenge. As for the strengths, when two very similarly designed but independent studies of the effects of any pharmacological agent give the same result, it is encouraging. Accordingly, the two studies in patients with cancer experiencing enduring psychiatric symptoms and given psilocybin or a comparator (Griffiths et al, 2016; Ross et al, 2016) deserve to be taken seriously. However, there have to be caveats. Are we confident that we understand the patient population? Did the trial design allow a clear question to be asked and were the outcomes meaningful?

\section{THE PATIENT POPULATION}

In the choice of patient group, why cancer patients? Ross et al (2016) suggested that a domain of distress they call existential/spiritual well being is particularly relevant to depression in cancer while Griffith et al (2016) emphasize that evidence for efficacy of conventional medication or psychotherapy is poor or even negative.

Symptoms of both depression and anxiety are relatively common in cancer patients. But, they are often not very severe and in fact patients may choose not to seek help in their treatment (Baker-Glenn et al, 2011). In a case series of 128 patients attending for their first session of chemotherapy for cancer, only about $20 \%$ indicated they would appreciate psychological help for distress, depression, or anxiety. Of these, most indicated they would appreciate the opportunity to speak to someone-but only one suggested a psychiatrist.

Significant depressive symptoms can occur in cancer patients of course and active screening of a large consecutive cohort suggested about $8 \%$ met criteria for a major depressive episode (Sharpe et al, 2004) and many are not offered treatment. A subsequent trial in 200 such patients was conducted to compare a nurse intervention (which included antidepressant medication as an option and problem solving) with treatment as usual (Strong et al, 2008). There was a clinically significant and sustained impact of intervention on depressive symptoms (and on anxiety and fatigue): $68 \%$ of the treated group achieved remission compared with $45 \%$ of the comparator group (odds ratio 3 (confidence interval: 1.6-5.5).

Thus, the case for a particular unmet need in cancer patients is actually quite difficult to sustain. The idea that cancer diagnosis poses a particular threat to existential/ spiritual well-being in some patients may be correct but there is a risk that one recruits into trials people with a particular interest in psychedelic experience, who are hence predisposed to endorse its benefits. They may not be representative of cancer patients in general. In the published study where it 
is reported, the rate of previous use of hallucinogens was indeed high (55\% in the Ross et al, 2016).

\section{THE TRIAL DESIGN}

In each of the two cancer studies, the design was a crossover, which compared, respectively, low-dose/high-dose psilocybin and niacin (placebo)/high-dose psilocybin. The subjective effects of the high dose consisted in heightened states of consciousness with marked emotional accompaniments (anxiety, tearfulness, and in a few cases, paranoid ideation). These effects were as expected, given the previous literature. It is difficult to see how blinding can be maintained because the subjective effects of drug were so florid. There was some uncertainty in the ratings by support staff, who supervised the sessions blind to dosing. However, overall one must assume the patients were usually unblinded by their experience on active drug. If so, it provided the kind of cue called a demand characteristic. That is anything that makes participants in an experimental study aware of what the experimenter expects to find or how participants are expected to behave. Such issues would also be difficult to avoid in judging outcomes, without great care in preserving raters to be blind.

\section{THE OUTCOME MEASURES}

The outcome measures of both trials are self, community, and clinician reports. Thus, they are entirely subjective, as most studies of antidepressants and anxiolytics have been. The demand problem has been noted already for patients, but it will also be problematic for third-party reports if patients communicate their own unblinding at interview. But, just as for other studies, symptoms alone are a problematic way of assessing outcome. In other words, they are not highly proximal to the disease process as for example research domain criteria dimensions have been suggested to be. But, they are also not distal enough for assessing the functional value of treatment either. More objective measures are possible. One could objectively measure simple motor activity or geolocation. Geolocation is particularly simple to obtain entirely passively from mobile phones. The resulting measure of time at home for example correlates well with depression severity in depressed bipolar patients (Palmius et al, 2016). In cancer patients, there is the further domain of medical care, which is known to be complicated by co-morbid depression. An increase in adherence to treatment or even efficacy could result from really effective treatment. Greater objectivity should contribute more to the picture in future research of psilocybin's potential role. Nevertheless, for the moment, subjective response remains the regulatory standard against which psychotropic drugs will be measured.

\section{DOES THE PSILOCYBIN EXPERIENCE REALLY BELONG IN MEDICINE?}

The unspoken assumption, which I think we both share, is that the use of psilocybin at this stage requires a medical justification. Certainly, it started in western society as a putative aid to psychotherapy, but of course, it has an older cultural history as a constituent of magic mushrooms. Many believed and believe that the justification for the use of such drugs lies in their capacity to open the doors of perception, as Aldous Huxley put it. On this view, access to such drugs should be a recreational right, like access to alcohol, cigarettes, and increasingly cannabis. As with cannabis, medical use may be expected to promote wider discretionary use for any reason. Some may still regard this as a red light for the development of medical indications.

However, there is an important corollary to the continuing illegal status of psychedelics. It seems to me paradoxical, even incredible, that such drugs should not be available for medical use in conditions for which euthanasia is already available. In Belgium, neuropsychiatric disorders were first reported under euthanasia legislation in 2004/5. Of the first such 100 patients considered for euthanasia between 2007 and 2011, 58 had depression. Forty-eight of the total were accepted for euthanasia (35 completed) and six others had died by suicide within 12 months from the end of the study. Most patients were female, aged 40-60 years. Euthanasia for psychological suffering is similarly available in the Netherlands and Luxemburg (Thienpont et al, 2015).

So, I think we need psilocybin in medicine but we should not forget the failures of human logic, which mean we need high-quality clinical trials:

"All who drink of this remedy recover in a short time, except those whom it does not help, who all die. Therefore, it is obvious that it fails only in incurable cases." (Galen in $180 \mathrm{AD}$ )

\section{HOW TO MOVE THE FIELD FORWARD (GMG AND RLC-H)}

Our shared interest in the development of psychedelics, and particularly psilocybin, for medical use is a major point of convergence. There may be a subtle difference in our views of the so-called 'mystical' elements of the psychedelic experience, ie, both of us see the term 'mystical' as problematic-but whereas GMG views the acute 'psychedelic experience' as irrelevant to the clinical development of psychedelics, RLC-H sees it as a potentially exploitable component-especially as it has been shown to be predictive of long-term clinical outcomes (eg, in Johnson et al, 2014; Bogenschutz et al, 2015; Griffiths et al, 2016; Ross et al, 2016; Carhart-Harris et al, 2016a,b). Perhaps the most notable point of divergence, however, relates to the choice of patient population for the clinical development of psilocybin for depression. For GMG, the most obvious and relevant unmet need is treatment-resistant depression (see below), and while RLC-H accepts that treatment resistance is often the first port-of-call for the development of a novel intervention, he feels that unipolar depression more generally, will prove a better indication for this treatment. In his view, psilocybin will be safest, most effective, and easiest to implement, prior to the treatment-resistant stage of illness.

Focusing on treatment-resistant depression for the moment, however, we both recognize that a significant number of patients treated first line with either a SSRI or CBT fail to respond adequately (Gaynes, 2009). Persisting symptoms lead to enduring chronicity of depression, and there is no consensus in existing guidelines on what to do 
next. Moreover, the efficacy of secondary intervention is often modest and new medications can introduce new side effects. The duration of distress with TRD and its economic impact are considerable. We agree that TRD represents a valid point in the treatment pathway, where a single psychedelic intervention might find a place; however, RLC-H questions whether patients must wait until their depression is significantly stamped-in before psilocybin can be considered, and based on the speed and duration of treatment responses seen in the trials listed above, it seems reasonable to ask whether early intervention with psilocybin could be prophylactic-and there is also the issue of SSRIs obstructing the potential therapeutic action of psilocybin.

If it is to be TRD, however, then patient recruitment can be based on pre-existing criteria (Sackeim, 2001) and patients meeting them will not be rare and should not be excessively treatment resistant. As noted earlier, there is a significant challenge to the issue of continuing medication, most commonly with SSRIs. There is anecdotal evidence that psychedelic effects are largely attenuated by ongoing treatment with SSRIs (Bonson et al, 1996) and perhaps with other antidepressants (Bonson and Murphy, 1996). Downregulation of 5-HT2A receptors is a feature of many different first-line antidepressant drugs (Muguruza et al, 2014), as well as second-line antidepressant medications (eg, atypical antipsychotics) with significant 5-HT2AR antagonist properties (Gray and Roth, 2001). Any trial would ideally be conducted in patients withdrawn from such drugs for at least 2 weeks or so, but we accept that this is not always straightforward (Baldwin et al, 2007).

Moving on from questions of the optimal patient population, both of us can see merit in a multiple dose trial comparing, for example, 1, 10 and $25 \mathrm{mg}$ of psilocybin. Such a design seems to overcome some of the problems any trial of a psychedelic will face. The ethical problem of equipoise seems satisfactory because we really do not know which dose, if any, will be effective, and patients can enter the study knowing that whatever group they are allocated to, they will receive active drug. The omission of a strict placebo control would be pragmatic in this sense, as expectation and preparation would be standardized. We know the highest dose of psilocybin will likely unblind participants and the expectation of a possible placebo would complicate recruitment. An approximation to an inert placebo condition may be met with the $1 \mathrm{mg}$ psilocybin arm, as such a dose is likely too low to produce appreciable subjective or physiological effects (Griffiths et al, 2016). The differences between a dose mainly producing perceptual distortion $(10 \mathrm{mg}$ ) and one more capable of producing the more profound, putatively 'transformative' aspects of the psychedelic experience $(25 \mathrm{mg})$ is also of scientific and clinical interest.

Comparing mechanisms and/or efficacy with an established treatment would be a next step to advance the evidence base for psilocybin for TRD. For example, psilocybin could be compared with ketamine since it has some similarities: rapid, single-dose efficacy, and obvious subjective effects during its infusion. Psilocybin's distinctive subjective effects and the implications of this for blinding would still remain a major challenge; moreover, as with ketamine, there will also remain the question of how much an acute response is sustained and whether a maintenance dose may be required.

The traditional view of the mechanism, whereby psilocybin works, emphasizes the importance of accompanying psychotherapy (Johnson et al, 2008; Richards, 2015). Accordingly, psychedelics administered without psychological support and/or a supportive environment may have limited antidepressant efficacy, and in very rare cases, could even worsen a patient's condition (Oram, 2014). We share the view that the presence of psychological support is an essential component of the psychedelic treatment model (Johnson et al, 2008) but we also recognize that the magnitude and nature of its contribution needs to be better defined and tested.

Pragmatically, we accept that minimizing the active psychological work of the therapy would be desirable (eg, therapy time is expensive) and scientifically, doing so would allow drug effects and dose to be better identified. Critically however, any such therapy minimization should not be allowed to jeopardize patient safety (Johnson et al, 2008). A future challenge will be to learn how psychological interventions can maximize the advantages of the psychedelic state. For example, we can imagine how cognitive therapy, attentional-bias training and/or de-sensitization could be investigated with or without psilocybin assistance.

In other respects, a psilocybin trial is easier to conduct than studies requiring continuing adherence to a daily oral dose of an antidepressant. Exposure to the treatment can be completely controlled and follow-up can be relatively pragmatic. It seems logical to determine an early proximal end point to prove initial impact of treatment and then to follow subsequent illness course as comprehensively as possible. In this way, we will be able to determine time to supplementary treatment, document recovery of symptoms and function, and perhaps objectify improvement using a simple frictionless measure of activity-like geolocation (Palmius et al, 2016).

In the short term, there will also be a need to demonstrate cost effectiveness. The requirement for psychological support and/or a supportive environment could be a major limitation of the psychedelic treatment model. However, direct medical costs need to be netted off against the social and economic costs of illness.

In summary, a door has been opened for the medical repurposing of psychedelics. The possibility exists that drugs like psilocybin can meet a major unmet need in the treatment of psychiatric disorders. For GMG, treatmentresistant depression is the most logical place to start because of the uncertainty around the choice of next-step treatment after an SSRI fails, and while RLC-H accepts this (CarhartHarris et al, 2016a,b), he looks forward to a time when an individual may receive psilocybin before the ruts of depression are allowed to deepen (Holtzheimer and Mayberg, 2011). Regardless of who the 'right' patient population might be eventually, a key challenge now is to design the optimal trial to demonstrate efficacy, agree its validity with regulatory authorities and fund it. 


\section{FUNDING AND DISCLOSURE}

GMG is a NIHR senior investigator; the views expressed are those of the author and not necessarily those of the NHS, the NIHR or the Department of Health. GMG holds a grant from Wellcome Trust, holds shares in P1vital and has in the past 3 years served as consultant, advisor or CME speaker for Angelini, MSD, Lundbeck (/Otsuka or/Takeda), Medscape, P1Vital, Pfizer, Servier and Shire. RLC-H is supported by the Alex Mosley Charitable Trust and his research has received support from the Beckley Foundation, as part of the BeckleyImperial Research Programme. RLC-H and GMG are currently advising Compass Pathways, a commercial initiative to develop psilocybin as a medicine.

\section{ACKNOWLEDGMENTS}

RLC-H would like to thank Samantha Strong for the illustrations contained in Figure 1.

\section{REFERENCES}

Abramson A (1959). The Use of LSD in Psychotherapy. Josiah Macy, Jr. Foundation: New York.

Baker-Glenn EA, Park B, Granger L, Symonds P, Mitchell AJ (2011). Desire for psychological support in cancer patients with depression or distress: validation of a simple help question. Psychooncology 20: 525-531.

Baldwin DS, Montgomery SA, Nil R, Lader M (2007). Discontinuation symptoms in depression and anxiety disorders. Int $J$ Neuropsychopharmacol 10: 73-84.

Belsky J (2016). The differential susceptibility hypothesis: sensitivity to the environment for better and for worse. JAMA Pediatr 170: 321-322.

Bogenschutz MP, Forcehimes AA, Pommy JA, Wilcox CE, Barbosa PC, Strassman RJ (2015). Psilocybin-assisted treatment for alcohol dependence: a proof-of-concept study. J Psychopharmacol 29: 289-299.

Bonson KR, Buckholtz JW, Murphy DL (1996). Chronic administration of serotonergic antidepressants attenuates the subjective effects of LSD in humans. Neuropsychopharmacology 14: 425-436.

Bonson KR, Murphy DL (1996). Alterations in responses to LSD in humans associated with chronic administration of tricyclic antidepressants, monoamine oxidase inhibitors or lithium. Behav Brain Res 73: 229-233.

Bouso JC, Gonzalez D, Fondevila S, Cutchet M, Fernandez X, Ribeiro Barbosa PC et al (2012). Personality, psychopathology, life attitudes and neuropsychological performance among ritual users of Ayahuasca: a longitudinal study. PLoS ONE 7: e42421.

Bradley PB, Elkes C, Elkes J (1953). On some effects of lysergic acid diethylamide (L.S.D. 25) in normal volunteers. J Physiol 121.

Busch AK, Johnson WC (1950). L.S.D. 25 as an aid in psychotherapy; preliminary report of a new drug. Dis Nerv Syst 11: 241-243.

Carhart-Harris RL, Bolstridge M, Day CMJ, Rucker J, Watts R, Erritzoe DE et al (2016a). Psilocybin with psychological support for treatment-resistant depression: six-month follow-up. The British Association for Psychopharmacology Summer Meeting. 17-20 July, Brighton, UK; Abstract.

Carhart-Harris RL, Bolstridge M, Rucker J, Day CM, Erritzoe D, Kaelen $\mathrm{M}$ et al (2016b). Psilocybin with psychological support for treatment-resistant depression: an open-label feasibility study. Lancet Psychiatry 3: 619-627.

Carhart-Harris RL, Erritzoe D, Williams T, Stone JM, Reed LJ, Colasanti A et al (2012a). Neural correlates of the psychedelic state as determined by fMRI studies with psilocybin. Proc Natl Acad Sci USA 109: 2138-2143.

Carhart-Harris RL, Kaelen M, Bolstridge M, Williams TM, Williams LT, Underwood R et al (2016c). The paradoxical psychological effects of lysergic acid diethylamide (LSD). Psychol Med 1-12.

Carhart-Harris RL, Kaelen M, Whalley MG, Bolstridge M, Feilding A, Nutt DJ (2015). LSD enhances suggestibility in healthy volunteers. Psychopharmacology 232: 785-794.

Carhart-Harris RL, Leech R, Williams TM, Erritzoe D, Abbasi N, Bargiotas $\mathrm{T}$ et al (2012b). Implications for psychedelic-assisted psychotherapy: functional magnetic resonance imaging study with psilocybin. Br J Psychiatry 200: 238-244.

Carhart-Harris RL, Muthukumaraswamy S, Roseman L, Kaelen M, Droog W, Murphy K et al (2016d). Neural correlates of the LSD experience revealed by multimodal neuroimaging. Proc Natl Acad Sci USA 113: 4853-4858.

Carhart-Harris RL, Nutt DJ (2010). User perceptions of the benefits and harms of hallucinogenic drug use: a web-based questionnaire study. J Subst Use 15: 283-300.

Carhart-Harris RL, Nutt DJ (2013). Experienced drug users assess the relative harms and benefits of drugs: a web-based survey. J Psychoactive Drugs 45: 322-328.

Carter OL, Hasler F, Pettigrew JD, Wallis GM, Liu GB, Vollenweider FX (2007). Psilocybin links binocular rivalry switch rate to attention and subjective arousal levels in humans. Psychopharmacology 195: 415-424.

Cohen S (1960). Lysergic acid diethylamide: side effects and complications. J Nerv Ment Dis 130.1: 30-40.

Cole JO, Katz MM (1964). The psychotomimetic drugs: an overview. JAMA 187: 758-761.

Cowen PJ, Browning M (2015). What has serotonin to do with depression? World Psychiatry 14: 158-160.

Daumann J, Wagner D, Heekeren K, Neukirch A, Thiel CM, Gouzoulis-Mayfrank E (2010). Neuronal correlates of visual and auditory alertness in the DMT and ketamine model of psychosis. J Psychopharmacol 24: 1515-1524.

Deakin JF, Graeff FG (1991). 5-HT and mechanisms of defence. J Psychopharmacol 5: 305-315.

Dressler WW, Balieiro MC, Ferreira de Araujo L, Silva WA Jr, Ernesto Dos Santos J (2016). Culture as a mediator of geneenvironment interaction: cultural consonance, childhood adversity, a 2A serotonin receptor polymorphism, and depression in urban Brazil. Soc Sci Med 161: 109-117.

Fiocco AJ, Joober R, Poirier J, Lupien S (2007). Polymorphism of the $5-\mathrm{HT}(2 \mathrm{~A})$ receptor gene: association with stress-related indices in healthy middle-aged adults. Front Behav Neurosci 1: 3.

Gasser P, Holstein D, Michel Y, Doblin R, Yazar-Klosinski B, Passie $\mathrm{T}$ et al (2014). Safety and efficacy of lysergic acid diethylamide-assisted psychotherapy for anxiety associated with life-threatening diseases. J Nerv Ment Dis 202: 513-520.

Gaynes BN (2009). Identifying difficult-to-treat depression: differential diagnosis, subtypes, and comorbidities. J Clin Psychiatry 70 (Suppl 6): 10-15.

Gouzoulis-Mayfrank E, Heekeren K, Neukirch A, Stoll M, Stock C, Obradovic M et al (2005). Psychological effects of (S)-ketamine and N,N-dimethyltryptamine (DMT): a double-blind, cross-over study in healthy volunteers. Pharmacopsychiatry 38: 301-311.

Gray JA, Roth BL (2001). Paradoxical trafficking and regulation of 5-HT(2A) receptors by agonists and antagonists. Brain Res Bull 56: 441-451.

Griffiths RR, Johnson MW, Carducci MA, Umbricht A, Richards WA, Richards BD et al (2016). Psilocybin produces substantial and sustained decreases in depression and anxiety in patients with life-threatening cancer: A randomized doubleblind trial. J Psychopharmacol 30: 1181-1197.

Griffiths RR, Richards WA, McCann U, Jesse R (2006). Psilocybin can occasion mystical-type experiences having substantial and 
sustained personal meaning and spiritual significance. Psychopharmacology 187: 268-283.

Grinspoon L, Bakalar JB (1979). Psychedelic Drugs Reconsidered. Basic Books: New York.

Grob CS, Danforth AL, Chopra GS, Hagerty M, McKay CR, Halberstadt AL et al (2011). Pilot study of psilocybin treatment for anxiety in patients with advanced-stage cancer. Arch Gen Psychiatry 68: 71-78.

Grof S (1979). Realms of the Human Unconscious: Observations from LSD Research. Souvenir Press: London.

Harmer CJ, Cowen PJ (2013). 'It's the way that you look at it'-a cognitive neuropsychological account of SSRI action in depression. Philos Trans R Soc Lond B Biol Sci 368: 20120407.

Hartogsohn I (2016). Set and setting, psychedelics and the placebo response: an extra-pharmacological perspective on psychopharmacology. J Psychopharmacol 30: 1259-1267.

Hendricks PS, Thorne CB, Clark CB, Coombs DW, Johnson MW (2015). Classic psychedelic use is associated with reduced psychological distress and suicidality in the United States adult population. J Psychopharmacol 29: 280-288.

Hermle L, Funfgeld M, Oepen G, Botsch H, Borchardt D, Gouzoulis E et al (1992). Mescaline-induced psychopathological, neuropsychological, and neurometabolic effects in normal subjects: experimental psychosis as a tool for psychiatric research. Biol Psychiatry 32: 976-991.

Hofmann A (1980). LSD: My Problem Child. McGraw-Hill: New York.

Hofmann A, Heim R, Brack A, Kobel H (1958). Psilocybin, a psychotropic substance from the Mexican mushroom Psilicybe mexicana Heim. Experientia 14: 107-109.

Holtzheimer PE, Mayberg HS (2011). Stuck in a rut: rethinking depression and its treatment. Trends Neurosci 34: 1-9.

Huxley A (1954). The Doors of Perception. On the author's sensations under the influence of the drug mescalin.. Chatto \& Windus: London.

Huxley A (1980). Moksha: Writings on Psychedelics and the Visionary Experience. Chatto and Windus: London. pp 1931-1963.

Johnson M, Richards W, Griffiths R (2008). Human hallucinogen research: guidelines for safety. J Psychopharmacol 22: 603-620.

Johnson MW, Garcia-Romeu A, Cosimano MP, Griffiths RR (2014). Pilot study of the 5-HT2AR agonist psilocybin in the treatment of tobacco addiction. J Psychopharmacol 28: 983-992.

Jokela M, Keltikangas-Jarvinen L, Kivimaki M, Puttonen S, Elovainio M, Rontu $\mathrm{R}$ et al (2007). Serotonin receptor 2A gene and the influence of childhood maternal nurturance on adulthood depressive symptoms. Arch Gen Psychiatry 64: 356-360.

Kaelen M, Barrett FS, Roseman L, Lorenz R, Family N, Bolstridge M et al (2015). LSD enhances the emotional response to music. Psychopharmacology 232: 3607-3614.

Kometer M, Schmidt A, Bachmann R, Studerus E, Seifritz E, Vollenweider FX (2012). Psilocybin biases facial recognition, goal-directed behavior, and mood state toward positive relative to negative emotions through different serotonergic subreceptors. Biol Psychiatry 72: 898-906.

Krebs TS, Johansen PO (2012). Lysergic acid diethylamide (LSD) for alcoholism: meta-analysis of randomized controlled trials. $J$ Psychopharmacol 26: 994-1002.

Lee MA, Shlain B (1992). Acid Dreams: The Complete Social History of LSD: The CIA, The Sixties, and Beyond. In: Rev. Evergreen (ed). Grove Weidenfeld: New York.

MacLean KA, Johnson MW, Griffiths RR (2011). Mystical experiences occasioned by the hallucinogen psilocybin lead to increases in the personality domain of openness. J Psychopharmacol 25: 1453-1461.

Mangini M (1998). Treatment of alcoholism using psychedelic drugs: a review of the program of research. J Psychoactive Drugs 30: 381-418.

McCabe C, Mishor Z, Cowen PJ, Harmer CJ (2010). Diminished neural processing of aversive and rewarding stimuli during selective serotonin reuptake inhibitor treatment. Biol Psychiatry 67: 439-445.

Moreno FA, Wiegand CB, Taitano EK, Delgado PL (2006). Safety, tolerability, and efficacy of psilocybin in 9 patients with obsessivecompulsive disorder. J Clin Psychiatry 67: 1735-1740.

Muguruza C, Miranda-Azpiazu P, Diez-Alarcia R, Morentin B, Gonzalez-Maeso J, Callado LF et al (2014). Evaluation of 5-HT2A and $\mathrm{mGlu}(2 / 3)$ receptors in postmortem prefrontal cortex of subjects with major depressive disorder: effect of antidepressant treatment. Neuropharmacology 86: 311-318.

Muthukumaraswamy SD, Carhart-Harris RL, Moran RJ, Brookes MJ, Williams TM, Errtizoe D et al (2013). Broadband cortical desynchronization underlies the human psychedelic state. J Neurosci 33: 15171-15183.

Oram M (2014). Efficacy and enlightenment: LSD psychotherapy and the drug amendments of 1962. J Hist Med Allied Sci 69: 221-250.

Osorio Fde L, Sanches RF, Macedo LR, Santos RG, Maia-de-Oliveira JP, Wichert-Ana L et al (2015). Antidepressant effects of a single dose of ayahuasca in patients with recurrent depression: a preliminary report. Rev Bras Psiquiatr 37: 13-20.

Pahnke WN (1966). Drugs and mysticism. Int J Parapsychol 8: 295-315.

Palhano-Fontes F, Andrade KC, Tofoli LF, Santos AC, Crippa JAS, Hallak JEC et al (2015). The psychedelic state induced by ayahuasca modulates the activity and connectivity of the default mode network. PLOS ONE 10: e0118143.

Palmius N, Tsanas A, Saunders KE, Bilderbeck AC, Geddes JR, Goodwin GM et al (2016). Detecting bipolar depression from geographic location data. IEEE Trans Biomed Eng (e-pub ahead of print).

Passie T (1996). Hanscarl leuner-pioneer of hallucinogen research and psycholytic therapy. Maps Newslett 7: 46-49.

Preller KH, Herdener M, Pokorny T, Planzer A, Kraehenmann R, Stampfli $\mathrm{P}$ et al (2017). The Fabric of meaning and subjective effects in LSD-induced states depend on serotonin 2A receptor activation. Curr Biol 27: 451-457.

Riba J, Anderer P, Jane F, Saletu B, Barbanoj MJ (2004). Effects of the South American psychoactive beverage ayahuasca on regional brain electrical activity in humans: a functional neuroimaging study using low-resolution electromagnetic tomography. Neuropsychobiology 50: 89-101.

Riba J, Romero S, Grasa E, Mena E, Carrio I, Barbanoj MJ (2006). Increased frontal and paralimbic activation following ayahuasca, the pan-Amazonian inebriant. Psychopharmacology 186: 93-98.

Richards WA (2015). Sacred Knowledge: Psychedelics and Religious Experiences. Columbia University Press: New York.

Roberts A (2008). Albion Dreaming: A Popular History of LSD in Britain. Marshall Cavendish: London.

Roseman L, Demetriou L, Wall MB, Nutt DJ, Carhart- Harris RL (2016). Psilocybin-assisted therapy increases amygdala responsivity to fearful faces, while reducing depressive symptoms after therapy in treatment-resistant depression. The British Association for Psychopharmacology Summer Meeting. 17-20 July, Brighton, UK; Abstract number C32.

Ross S, Bossis A, Guss J, Agin-Liebes G, Malone T, Cohen B et al (2016). Rapid and sustained symptom reduction following psilocybin treatment for anxiety and depression in patients with life-threatening cancer: a randomized controlled trial. J Psychopharmacol 30: 1165-1180.

Rucker JJ, Jelen LA, Flynn S, Frowde KD, Young AH (2016). Psychedelics in the treatment of unipolar mood disorders: a systematic review. J Psychopharmacol 30: 1220-1229.

Sackeim HA (2001). The definition and meaning of treatmentresistant depression. J Clin Psychiatry 62(Suppl 16): 10-17.

Sanches RF, de Lima Osório F, Dos Santos RG, Macedo LR, Maia-de-Oliveira JP, Wichert-Ana L et al (2016). Antidepressant 
effects of a single dose of ayahuasca in patients with recurrent depression: a SPECT study. J Clin Psychopharmacol 36: 77-81.

Schmid Y, Enzler F, Gasser P, Grouzmann E, Preller KH, Vollenweider FX et al (2015). Acute effects of lysergic acid diethylamide in healthy subjects. Biol Psychiatry 78: 544-553.

Sessa B (2012). The Psychedelic Renaissance: Reassessing the Role of Psychedelic Drugs in 21st Century Psychiatry and Society. Muswell Hill Press: London.

Sharpe M, Strong V, Allen K, Rush R, Postma K, Tulloh A et al (2004). Major depression in outpatients attending a regional cancer centre: screening and unmet treatment needs. Br J Cancer 90: 314-320.

Schunemann HJ, Fretheim A, Oxman AD (2006). Improving the use of research evidence in guideline development: 9. Grading evidence and recommendations. Health Res Policy Syst 4: 21.

Stevens J (1987). Storming Heaven: LSD and the American Dream. Paladin: London.

Strassman RJ, Qualls CR (1994). Dose-response study of N,Ndimethyltryptamine in humans. I. Neuroendocrine, autonomic, and cardiovascular effects. Arch Gen Psychiatry 51: 85-97.

Stoll W (1947). Lysergsäure-diäthyl-amid, ein Phantastikum aus der Mutterkorngruppe. Schweiz Arch Neur 60: 1-2.

Strong V, Waters R, Hibberd C, Murray G, Wall L, Walker J et al (2008). Management of depression for people with cancer (SMaRT oncology 1): a randomised trial. Lancet 372: 40-48.

Thienpont L, Verhofstadt M, Van Loon T, Distelmans W, Audenaert K, De Deyn PP (2015). Euthanasia requests, procedures and outcomes for 100 Belgian patients suffering from psychiatric disorders: a retrospective, descriptive study. BMJ Open 5: e007454.

Valle M, Maqueda AE, Rabella M, Rodriguez-Pujadas A, Antonijoan RM, Romero S et al (2016). Inhibition of alpha oscillations through serotonin-2A receptor activation underlies the visual effects of ayahuasca in humans. Eur Neuropsychopharmacol 26: 1161-1175.

van Amsterdam J, Nutt D, Phillips L, van den Brink W (2015). European rating of drug harms. J Psychopharmacol 29: 655-660.

Vollenweider FX, Leenders KL, Scharfetter C, Maguire P, Stadelmann O, Angst J (1997). Positron emission tomography and fluorodeoxyglucose studies of metabolic hyperfrontality and psychopathology in the psilocybin model of psychosis. Neuropsychopharmacology 16: 357-372.

Vollenweider FX, Vollenweider-Scherpenhuyzen MF, Babler A, Vogel H, Hell D (1998). Psilocybin induces schizophrenia-like psychosis in humans via a serotonin-2 agonist action. Neuroreport 9: 3897-3902.

Waldman AA (2017). A really good day: how microdosing made a mega difference in my mood, my marriage, and my life. Knopf Publishing Group: New York.

Wasson RG (1957). Seeking the magic mushroom. LIFE Magazine 49: $100-102$.

Watts R, Day C, Krzanowski J, Nutt D, Carhart-Harris R (2017). Patients' accounts of increased 'connection' and 'acceptance' after psilocybin for treatment-resistant depression. J Hum Psychol (in press).

Wolfe T (1968). The Electric Kool-Aid Acid Test. Farrar, Straus and Giroux: New York. 